\title{
Experiences and Challenges of Struggling Readers in the Framework of Modular Distance Learning
}

\author{
Simplicio J. Libre III ${ }^{1}$, Dr. Ronald S. Decano ${ }^{2}$ \\ ${ }^{1}$ Graduate Student, Doctor of Philosophy in Educational Management, Davao del Norte State College, Philippines \\ ${ }^{2}$ Dean, Institute of Advanced Studies, Davao del Norte State College, Philippines
}

\begin{abstract}
Reading is a macro skill in English that needs to be mastered in order to learn other subject areas. With the paradigm shift in education from face-to-face to Modular Distance Learning, non-readers and slow readers are left out from learning necessary skills. This primarily led to conducting this study and interviewed fifteen (15) non-readers and slow readers learning under Modular Distance Learning. QualitativePhenomenology is used in this research using In-Depth interview (IDI) and Focused Group Discussion (FGD) to interpret the challenges and experiences of learners that cause academic underachievement. The interview focus is primarily on the struggles, experiences, and motivations of Junior high School and Senior High School learners in learning under Modular Distance Learning. Reading difficulty, Reading as essential for Communication, Need for Communication, Comprehension Difficulty, Grammar difficulty, writing and composition difficulty and mispronunciation were some of the themes that emerged. It is recommended that an introduction of a sustainable reading program, assessment of individual reading level, homogeneity of reading level in a class, and monitoring and success evaluation shall be implemented to cater to the development of these learners' reading literacy leading academic achievement.
\end{abstract}

Key Words- Reading, Academic Achievement, Modular Distance Learning, non-readers, slow readers

\section{INTRODUCTION}

$\mathrm{T}$ he introduction of Modular Distance Learning in the Philippines received positivity and criticism (Kintanar et al., 2021). Its implementation across countries widely increased educational gaps, especially to non-readers and struggling readers. Questions clouded its implementation with common questions and confusions relating to reading literacy among non-readers, slow readers, and struggling readers (Salamuddin, 2021).

Reading as a macro an English macro skill is required for the mastery of other skills that leads to literacy in the primary ground for most processes in learning (Kennedy et al., 2012). Making inferences while reading appears a concern for learners (Pretorius, 2000). Inferring that reading is necessary for an individual to learn and be competent in many aspects of academic achievement.

UNESCO (2000) reported 1, 576, 021, 818 affected learners out of $91.3 \%$ total enrolled learners in 188 countries in all levels of learning in 188 countries in all levels while reading is one of the most important predictors of success in learning (Zhan et al., 2016)
A significant impact is stressed on the recurrence of illiteracy from parents to children (Matshe, 2014). Early reading abilities should be developed at an early age (Asri, 2021; Zhan et al., 2016). Attention to this ability is needed for optimum development. Comprehension of the reading materials has a connection to reading skills (Perfetti, 2007).

Teachers play an essential role in learning reading (Bertram, 2006); however, the closure of schools due to the global pandemic calls for an emergency among non-readers and slow readers (Ayu et al., 2021). Both morphological and phonological awareness are essential in developing reading ability (Mahony et al., 2000).

Academic achievement of non-readers is a common knowledge in modern classroom (Whitten et al., 2016). Teacher-student relationship must be established to develop reading ability (B \& Abhijith, 2014).but, with the closure of schools today, this is impossible.

The pandemic induced school closures shifted the Philippine Education system to look for ways for education continuity (Arnado et al., 2021). Over 27,770,263 learners from Kindergarten to Grade 12 were enrolled in the school year 2019-2020 excluding the schools overseas. This explains that Philippine Education must maintain these figures and keep the enrollment (DepEd, 2020). A response for improved literacy shall cater to many learners shall not be impeded by any academic disturbance (Equipado \& Asis-gilbas, 2021).

Understanding what the learners read and the ability to decode symbols were some of the problems they encounter (Bagolong et. al., 2021). Additionally, reading practice, content, and learning conditions were some of the indicators for successful reading (Palma \& Madrigal, 2021). Extensive reading programs also disables learners' reading ability (Lituanas, $\mathrm{P}$. M., Jacobs, G. M., \& Renandya, 2001).

With reading as the basic foundation for learning, closure of school and distance learning disables reading practice and producing struggling readers (Mantilla, 2020). Parents, on the other hand, face struggles in the abrupt shift of Philippine Education framework (Bayod \& June, 2021). As partners, parents, teachers, and learners need to work together for better learning, especially reading (Guan \& Benavides, 2021).

Bantacan National High School implemented Modular Distance Learning, one of the adoptions of distance learning that DepEd introduces. There is a need to reinforce reading 
instruction (Mirasol \& Topacio, 2021) in the framework of Modular Distance Learning. Modality threatens the reading ability of non-readers and slow readers in successfula academic achievement (Woodward \& Talbert-Johnson, 2009).

Disregarding non-readers and slow readers threaten "quality instruction" (Pretorius, 2000). Mainstreaming them would allow illiteracy and dissatisfaction (Forlin, 2010). Modified instruction should be introduced to allow sustained monitoring and evaluation for non-readers and slow readers (Hurry \& Sylva, 2007). A considerable strategic intervention for non-readers and slow readers who struggle in the Modular Distance Learning Modality framework must be operationalized to make learning meaningful and elevate the quality of instruction amid distance learning.

\section{METHODOLOGY}

\section{Research Design}

In this study, the Qualitative-Phenomenology method is utilized. Qualitative-Phenomenology is used to provide a standpoint of non-readers, slow readers, and readers in the frustration reading level. Phenomenology, in the most considerable sense, aims to create a bigger picture out of what was really happening. Phenomenology contributes to a deeper understanding of lived experiences, making meaning and essence of human experience (Moerer-Urdahl \& Creswell, 2004)

\section{Research Local and Sampling}

Fifteen (15) non-readers and slow readers of Bantacan National High School will be the subjects of this study as reported from the actual number of non-readers and slow readers in the School Reading Inventory Report for the school year 2020-2021. These learners fall in the struggling readers' category as reported by the Reading Coordinator.

\section{Research Environment}

Lerners from Bantacan National High School shall be the research environment for this study. Bantacan National High School is located at Barangay Bantacan, a boundary barangay in the municipality of Ne Bataan and Compostela, both in the province of Davao de Oro.

\section{Research Instrument}

A structured research interview guide will be used in gathering data for the research. The interview guide is validated by a panel of internal and external examiners to ensure its reliability and validity. For the purpose of collecting essential research data, Convenience Purposive sampling will be used. Etikan (2016) discussed that Convenience-Purposive Sampling is an economical nonprobability sampling used in research that depends on the researcher's judgments whereas to include research participants based on time availability, geographic location, access, and essential contribution to the study.

\section{Data Analysis and Collection Procedure}

As it holds with the Qualitative-Phenomenological research method, the data collected through interviews will be analyzed and interpreted. Before the interview, each research participant is given Informed Consent Form allowing the researcher to record and use their responses in the study. After the fifteen (15) participants have agreed, the researcher will continue with the data gathering.

Responses were transcribed in a verbatim manner and interpreted to establish rigor and trustworthiness (Halcomb \& Davidson, 2006; Poland Blake, 1995). The researcher's intention is only to present a standpoint of each research participant about their struggles, difficulties, and experiences in reading in the landscape of Modular Distance Learning Modality.

Verbatim transcription of recorded information and thematic presentation of data is presented. Online Focus-Group Discussion (FGD) and In-Depth Interview (IDI) are used in the data gathering using a structured interview guide.

To assist the research participants, the researcher will translate the questions about their experiences, challenges, and motivations in learning under modular distance learning amid their being a non-reader or slow readers.

\section{RESULTS AND DISCUSSION}

What are your experiences in reading in Modular Distance Learning?

Reading is Difficult. Learner's challenges in reading are its difficulty to understand. The difficulty of English is common among school-age since language is a complex area that needs concentration and a thorough understanding of the subject's totality. Teachers' capacity to teach, comprehension, and constant practice appears to be a problem in achieving competence in reading. As reflected in the responses, the difficulty of the language is evident.

Need of translation. As part of the scaffolding, reading English uses translation so that topics taught are extensively understood. This has made every learner get a deeper appreciation of English language and its importance. But when the content is in Philippine or Filipino language, these learners can grasp some of the ideas and it is easier that English.

Also, the Apprehension of Unfamiliar words becomes a problem. Understanding unfamiliar and high-sounding words are a common dilemma in reading. It becomes more challenging to read when there is no dictionary or any reference to aid in understanding. Pronunciation of unfamiliar words is even more complicated since it requires excellent knowledge of the phonological property of a word.

Comprehension difficulty. Respondents stressed out that it is most difficult when they cannot comprehend what they are reading. The reading process is useless, and that the time spent in reading is wasted. Reading difficulty is naturally 
difficult to understand when learners cannot read. Respondents confided that they have difficulty in comprehension because they have difficulty reading and identifying words.

What are the challenges you encounter in reading learning under Modular Distance Learning?

Development of Language Competence. Participants have confided that they have the difficulty in the development of the competence of the English language since they do not know how to assimilate what they have read from the meanings they have.

Difficult to understand. Common to all non-readers and slow readers, the reading text cannot be understood especially English with these learners' inability to decode the meaning of the text. The amount of the text also matters as well as the writing style of the author and language of text origin.

Speaking Difficulty. The absence of mimicry and practice in Modular Distance Learning is a factor for limited learning. as exposed with the participants, they have the difficulty in speaking the language because they do not have the model in their homes. They also suggest that learning especially reading is better in a traditional classroom.

Reading Comprehension difficulty. Comprehension with the reading text in Modular Distance Learning is also difficult for learners. It is founded in the study that learners get bored practicing reading when they do not understand what they have read. As a result, they will not continue answering their school activities. Understanding their school work is limited in Modular Distance Learning especially for non-readers and slow readers.

Oral Language fluency. Mimicry is a factor in oral language in a traditional classroom. Hence, it was found out that speaking in English is very difficult to non-readers and slow readers as these skills are closely associated. Modelling approach is essential to struggling readers in developing oral language fluency.

Difficulty in grammar, Writing, and Composition. With reading capacity in mind, difficulty in grammar, writing, and composition is normal. Learners' inability to write their own composition and their ability in grammar is limited in the framework of Modular Distance Learning. This discussion has emerged during the interview with the participants stated that guided practice would allow them higher achievement level in school than in their homes.

Mispronunciation. Part of reading comprehension is pronunciation. Some words have similar pronunciations but different meanings. Homophones are factors that affect the capacity to understand the reading material.

What are your motivations in learning to read in Modular Distance Learning?

Self-proficiency. Emerged in the interview that learners' motivation in learning to read in the framework in Modular
Distance Learning is for self-proficiency. It was founded that nothing can help these learners except themselves alone and they need to learn to read for self-improvement and proficiency.

To understand. To understand other subjects that required reading, participants primarily discussed that it motivates them to learn to read to be able to understand other subjects. They pointed out that they need to be able to read to understand other subjects.

For own self. As motivation, respondents stated that learning to read is for themselves. They have stated that they need to learn to read to help themselves and enhance their scholastic capacity. They should learn how to read so that learners can help themselves.

To finish studies and self-improvement. The learners' primary goal is to finish their studies and for self-improvement. In doing this, they need to learn how to read first. Reading can help them in finishing their education and improve themselves for a wider opportunity. Reading also helps them in improving themselves so that they can be successful someday. Academic achievement means that they can read, comprehend, and write.

\section{DISCUSSION}

The themes that emerged from the interview includes essential and helpful, essential for communication, enrichment for learning, difficult, Code-switching, Vocabulary Development, Pronunciation difficulty, Oral Reading Fluency, Grammar Difficulty, and Writing and Composition Difficulty.

\section{Experiences in Reading}

Essential and Helpful. As a result of the study, it was revealed that perceptions of learners in reading are; essential and helpful, reading is difficult, and reading is difficult to comprehend. The experiences of learners in reading in a framework of Modular Distance Learning have been very difficult for them. However, they keep on learning to read because they saw its importance as essential tool in communication.

Essential for Communication. Participants revealed that reading fluency is essential for communication. It was found out in the study that these struggling readers view reading as essential for communication.

Enrichment for learning. It was found out that reading enhances the mind to think critically. According to one of the participants, reading helps you advance to higher platform of learning. reading also is an enabler in understanding other subjects.

It also emerged that learning reading independently is difficult. One of the reasons that emerged is the availability of resources. They have limited access to technologies as they were at their homes and without help from parents and family members. Reading is even made difficult because also of the limited use of the language in the community. 
Oral Language. Oral language is complex for learners who are learning under Modular Distance Learning. For schools that implements Modular Distance Learning is learning delivery amidst pandemic, most of the eight (8) subject areas use English as the instructional channel. Learners need to answer and explain their academic work but cannot accomplish this due to limited oral language fluency.

This is caused by the difficulty and exposure of every learner to the use of language. Speaking learners' ideas have become a burden, especially since they have difficulty constructing sentences in explanation, discussing, and speaking. Participants are challenged by speaking the oral language fluently.

Language is incorporated in the daily discussion in the weak points that they do not know the essential and even understand the teacher teaching language. On the other hand, a strong point is emphasized on the exposure to reading since they create an 'incidental' noticing forming a standard feature of the language (Mohammadzadeh MohammadAbadi et al., 2012)

\section{Challenges in Reading}

Code-switching. Since the difficulty of oral language is ineviable. As part of scaffolding, translation and codeswitching are used to achieve the common understanding of language.

Vocabulary Development. Participants disclosed that their understanding toward new words is shallow. It is evident that their opportunity in using new words is limited, thus exposure to learning new words, however limited.

Henriksen (1999) proposed that lexical development requires lexical competence, depth of knowledge, and the productive use ability. To develop vocabulary competence, it is necessary to practice the use of the newly acquired vocabulary. Vocabulary practice is also rooted in learners' ability to read and remember words. Participants say that their ability to develop linguistic competence requires the ability to remember and practice.

Exposure to words facilitates vocabulary competence and development among non-readers and slow readers. Fluency of newly acquired vocabulary is increased through exposure, use, and repeated practice (Brent \& Siskind, 2001). To make vocabulary functional is to enhance through repeated practice and exposure.

The ability to decode reading text is rooted in the reading difficulty. Learners have difficulty in organizing the ideas presented in the text and interpreting them to orally explainable language. The type of the material, length of the reading material read, and writing styles of the author are some of the problems involved in reading comprehension.

Duke \& Pearson (2004) reiterated that an effective reading comprehension activity involves lots of time spent in reading, types of reading materials, frequent exercise and vocabulary rich materials, a range of reading genres in practice, and an environment where high quality talk about the text is expected. These factors for adequate reading comprehension for non-readers and slow readers are absent in Modular Distance Learning. A support is expected for learners to learn to read and enhance reading comprehension.

Pronunciation. Pronunciation among non-readers and slow readers is more than theories. It must be viewed as integral and crucial part of learning reading. Teachers should help and assist learners needs and should repeatedly monitor their progress. In doing this, learners' self-confidence is elevated and can harness their potential, making reading comprehension contribute to learners' overall communicative power.

Oral Reading Fluency. With reading comprehension as the ability to decode printed symbols, oral reading fluency is also affected by the type of text, reading ability, and purpose in reading. Participants exposed those common problems they encounter in oral reading fluency are mispronunciation, reading difficulty, inability to identify question marks, lack of confidence, and speaking ability.

Learners' speaking ability is influenced by language rules, intonation, grammar, and stress compared to their native language. The availability of pronunciation practice and modeling is absent in Modular Distance Learning. Learners cannot achieve oral fluency with the absence of modeling and practice with frustration, instructional, and independent readers are among reading levels as cited in the work of (Jenkins et al., 2005). Producing sounds needs the guidance of the teachers of a physical classroom.

With decoding and comprehension as significant component of reading. Participants proved this by citing that they do not know how to put stress and often mispronounce words due to absence of guidance of a teacher.

Grammar. The ability of learners to learn grammar is challenged by their ability to remember the grammatical rules that governs the use of grammar. Learners' ability to identify punctuation marks, properties and different parts of speech and its uses, and appropriate usage of each word form makes it easy for non-readers and slow readers to read and comprehend. Providing essential and relevant reading materials to learners and providing an engaging learning experience would allow learners to learn grammar (Wang \& Smith, 2013).

Additionally, the degree of teacher monitoring and learner engagement also causes learners to learn grammar. As espoused by the respondents, because of their inability to master grammar rules, they tend not to speak aloud and read to avoid mockery. This now hampers emotional and psychological dealings among these group of learners.

As influenced by reading, learning grammar is correlated with its use, rules, and properties. Non-readers and slow readers are confused with what rule to follow in a situational problem solving. Traditional teaching grammar technique like PPP (Present-Practice-Produce) sometimes doesn't work because learners cannot find the importance in learning grammar. 
Word group analysis and its different combinations also hinder in studying grammar (Noroozi, 2018)

Today's modular learning delivery impedes learners' ability to learn grammar effectively since teachers cannot properly guide them. Allowing this to happen produces a wide disparity of learning gap that challenges both learners and the educational system.

The ability of the teachers to remotely teach learners with grammar and its complexities would require the school and learners' family with their time, devotion, and effort coupled with technological infrastructure, innovative teaching and learning technique, and reading ability. As linked to reading, grammar should also focus on teaching the language that needs a great time and effort to teach.

Writing and Composition. Writing competency is significantly related to language proficiency and grammatical errors. Writing competence has a higher correlation to English subskills. The ideas learners presented in their writing topics are not original compositions and are only copied in books and other printed materials.

This scenario is significantly linked to learners' inability to read. As reading ability increases, the imagination also increases that allows the learners to write original composition. Their ability to write influenced by their language which is acquired by their constant reading practice. Decoding ideas also influences learner's ability to write and create their own composition.

The ability of learners to normalize writing should create an impact among readers. Hence, rooted in practical reading skills, non-readers and slow readers should first learn how to read for them to write. Also linked to the idea of constant practice, non-readers and slow readers should also practice writing.

Writing is a form of unique learning. Writing is unique and involves process-and-product attributes representing a particular form of learning (Emig \& Emig, 2007). Reading and writing is considered second-order processes that involve special skills in learning. As a particular way of learning, learners in a tribal school find it difficult to write that their foundation in combining words into sentences is not yet established. They find writing arduous because of their incapacity to formulate their ideas using English as the target language.

\section{Motivations in Reading}

Reading is one of the learner's skills that would mean quality education. Masgoret and Gardner (2003) have expounded that academic and language achievement depends on motivation which is present to all individuals who want to learn. Hence, understanding and relating some printed and advertising media through reading is also a great motivation among learners.

Dörnyei (2009) wrote that motivation must not relate to attitude. It must be separated since attitude is used in social psychology with function in a social context while motivation, as defined by motivational psychologists, suggests movement. This connotes that there should be movement and development in motivation to read.

Finally, finishing the studies, perfecting the test, and using language for employment are also great motivations in learning English. Naturally, the very aim in learning a language is to perfect the examinations in school. When they get good grades, they will eventually finish their studies, resulting in a profitable job. All these are connected in learning English.

\section{Suggestion for further work}

Grouping learners according to Reading Level. Upon enrollment, learners should be assessed according to their reading ability to be grouped and given appropriate learning activities. Non-readers should be given developmentally appropriate enrichment activities that would cater to their needs and develop their confidence. Immersing them in the mainstream education would mean that they are left out and create a confidence gap. School administration, teachers, and parents should investigate ways to solve this and ensure that these groups of learners are given attention and proper guidance.

As a program, assessment and identification of their reading level capacity enable the school leadership and parents to look for ways to remediate this. Grouping them will easily teach teachers and schools how to teach them and improve their reading ability.

Second, Strengthening Reading Instruction in Secondary Schools will also help to solve this problem. A strengthened reading program in secondary schools will improve the reading ability from Junior High School to Senior High School. The introduction of remedial reading instruction specifically designed for secondary school students will developmentally increase their ability to read and increase their reading capacity.

Focusing on word identification and sound production is the first skill for learners to develop their ability to comprehend the text, produce the sounds orally, identify grammatical rules, and increase vocabulary. These skills are shared among learners when they know how to read and improve their reading potential.

Allowing more teachers to focus on the reading ability of every non-reader and slow readers does decrease illiteracy. Teachers and schools should focus on strengthening the reading programs in every secondary school even in distance learning.

Thirdly, a Reading Intervention and Remedial Plan designed for non-readers and slow readers shall also be introduced. To continue the instruction among these learners, especially in reading instruction, an intervention plan specifically designed to monitor and assess the progress of non-readers and slow 
readers in the context of modular distance learning shall also be introduced.

Rooting from the continuity of learning, reading instruction shall also be included in the learning continuity plan in distance learning. A strategic intervention plan shall intervene the reading instruction aside from learners answering modules. School administrators and teachers shall also discuss that reading is a critical factor for learners in answering their learning modules and parallel assessment, hence reading fundamental in every aspect of learning. This intervention plan should also focus on producing literate learners able to read and identify words and letters.

Fourth, a Diversified Reading and Learning Materials shall also be expected to schools and teachers. Diversified reading and learning materials that focus on every learner's ability and reading experience shall be introduced to cater to their need in reading. Developmentally appropriate reading materials shall be given to learners as well as constant monitoring and checking will increase their reading ability.

Fifth, Constant Communication among Learners and Parents is a key to improved reading instruction. Communicating the needs of every learner is necessary for them to learn reading. Constant assessment is also a key factor for improving reading ability. Students and parents shall also be communicated so that needs assessment shall be communicated with.

Lastly, school administrators and academic heads shall monitor reading intervention instruction implementation for improved results. School leaders shall ensure that reading intervention plan is implemented correctly. It is also recommended that school leaders assess the improvement among learners so that they can have a direction in the reading plan implementation.

\section{Implications for Future Research}

As revealed in this study, benchmarking on the findings of this research will increase studies about reading instruction among non -readers and slow readers even in face-to-face classes. Researchers may also focus on the academic achievement of learners of non-readers and slow readers in the context of modular distance learning.

Moreover, making this research a benchmark shall also make future researchers look and develop reading programs fit for any situation for continued reading instruction. Resiliency of reading program is desired to reduce literacy and increase academic performance among learners. A factor that many researchers look into for improved national literacy goals.

Another is the ability of school leaders, parents, teachers, and learners to achieve a sense of responsibility and co-ownership. Sense of co-ownership and responsibility is also an excellent factor for improving reading fluency among non-readers and slow readers. Owning one's learning and increase a sense of responsibility for self-development will increase effectivity in any program.
Finally, emerging researchers may also focus on many reasons connected to reading fluency such as comprehension, grammar, vocabulary, oral language fluency, and ability to write composition and writing. These competencies also affected by the lack and inability to read. Researchers may also focus on this group of learners' academic achievement in other subject areas as subject to the ability to read and decode printed symbols.

\section{ACKNOWLEDGEMENT}

In a world that views education as a neutralizing agent for change, this is for you. I believe that we would create an environment where everyone is included, cherished, and celebrated. This academic work will not be completed without the help of the following: Dr. Ronald S. Decano, Dean of the Institute of Advanced Studies of Davao del Norte State College, for the encouragement to pursue this travail. To the panel of examiners for intricate examination of the parts of this study. To my family and friends for the untiring support and encouragement. To the learners of course, without you this will not come into being. And lastly, to our heavenly creator, for the guidance and immeasurable kindness whenever I feel weak.

\section{REFERENCES}

[1] Allington, R. L. (1983). Fluency: The Neglected Reading Goal. The Reading Teacher, 36(6), 556-561. http://www.jstor.org/stable/20198272

[2] Arnado, J. M., Jabal, R. F., Poa, M. R. J. A., \& Viray, T. C. (2021). Trust in pandemic-induced online learning: Competitive advantage of closure and reputation. International Journal of Sociology of Education, 10(2), 193-217. https://doi.org/10.17583/rise.2021.7088

[3] Bagolong, N. A., \& Usop, A. M. (2021). Reading Skills of Elementary Pupils as Basis for an Intervention Plan: The Case of Don E. Sero Elementary School, Philippines. JPAIR Institutional Research Journal, 16(1), 1-1.

[4] Beck, I. L., McKeown, M. G., \& McCaslin, E. S. (1983). Vocabulary Development: All Contexts Are Not Created Equal. The Elementary School Journal, 83(3), 177-181. https://doi.org/10.1086/461307

[5] Brent, M. R., \& Siskind, J. M. (2001). The role of exposure to isolated words in early vocabulary development. Cognition, 81(2), 33-44. https://doi.org/10.1016/S0010-0277(01)00122-6

[6] Dabaghi, A., \& Tavakoli, M. (2009). A Comparison of the Effects of Corrections on Definite/Indefinite Articles and Regular/Irregular Past Tense Forms: A Case of Iranian EFL Learners. The Asian EFL Journal Quarterly, 11(4), 31-57. http://asian-efl-journal.com/December-2009.pdf

[7] DepEd Order No. 12. Series of 2020. Adoption of the Basic Learning Continuity Plan for School Year 2020-2021 in the Light of the Covid-19 Public Health Emergency

[8] Dörnyei, Z. (2009). Individual differences: Interplay of learner characteristics and learning environment. Language Learning, 59(SUPPL. 1), 230-248. https://doi.org/10.1111/j.14679922.2009.00542.x

[9] Duke, N. K., \& Pearson, P. D. (2004). Effective Practices for Developing Reading Comprehension. What Research Has to Say about Reading Instruction. 205-242.

[10] Emig, J., \& Emig, J. (2007). Writi g as a m o d e Of Learning. 28(2), 122-128. chromeextension://efaidnbmnnnibpcajpcglclefindmkaj/viewer.html?pdfur $1=$ 
[11] Etikan, I. (2016). Comparison of Convenience Sampling and Purposive Sampling. American Journal of Theoretical and Applied Statistics, 5(1), 1. https://doi.org/10.11648/j.ajtas.20160501.11

[12] Hesse, D. (2010). The Place of Creative Writing in Composition Studies. College Composition and Communication. College Composition and Communication, 62(1), 31-52.

[13] Jenkins, J. R., Zumeta, R., \& Dupree, O. (2005). Measuring

[14] Gains in Reading Ability with Passage Reading Fluency. Learning Disabilities Research and Practice, 20(4), 245-253. https://doi.org/10.1111/j.1540-5826.2005.00140.x

[15] Mizera, G. J. (2006). Working memory and L2 oral fluency. Arts and Sciences, PhD, 175. chromeextension://efaidnbmnnnibpcajpcglclefindmkaj/viewer.html?pdfur 1

[16] Moerer-Urdahl, T., \& Creswell, J. W. (2004). Using Transcendental Phenomenology to Explore the "Ripple Effect" in a Leadership Mentoring Program. International Journal of Qualitative Methods, 3(2), 19-35. https://doi.org/10.1177/160940690400300202

[17] Mullis, I. V. S., Martin, M. O., Foy, P., \& Drucker, K. T. (2012). PIRLS 2011 International Results in Reading. In TIMSS \& PIRLS International Study Center. http://timss.bc.edu/pirls2011/reports/downloads/P11_IR_FullBook .pdf

[18] NamazianDost, E., Fatahi, M., \& ... (2019). The relationship between Iranian upper-intermediate EFL learners' contrastive lexical competence and their use of vocabulary learning strategies. International Journal of ..., 7(28). https://papers.ssrn.com/sol3/papers.cfm?abstract_id

[19] Noroozi, M. (2018). Task-based Language Teaching versus Present, Practice, Produce: Efficacy in Language Learning and Assessment Recommended Citation. https://digitalcommons.fiu.edu/etd/3874

[20] Pourhosein Gilakjani, A. (2011). A Study on the Situation of Pronunciation Instruction in ESL/EFL Classrooms. Journal of Studies in Education, 1(1). https://doi.org/10.5296/jse.v1i1.924 [21] Wang, S., \& \& $\quad$ Smith,
(2013).Reading_and_grammar_learning_t.PDF. Learning \& Technology, 17(3), 117-134.

[22] Howard, J., \& Millar, S. (2009). The applicability of principles for instructed second language learning: A South Korean perspective. Asian EFL Journal, 11(4), 31-57.. http://asian-efljournal.com/December-2009.pdf\#page $=31$

[23] Masgoret, A. M., \& Gardner, R. C. (2003). Attitudes, motivation, and second language learning: a meta-analysis of studies conducted by Gardner and associates. Language learning, 53(1), 123-163. Retrieved from http://onlinelibrary.wiley.com/doi/10.1111/1467-9922.00212/full

[24] Walqui, A. (2006). Scaffolding Instruction for English Language Learners: A Conceptual Framework. Teacher Professional Development Program, West Ed, USA. Retrieved from

https://pdfs.semanticscholar.org/eeaf/a59d9a254ac843f9d8fb94ae bd017dae6b76.pdf

[25] UNESCO (2020). Global Monitoring of School Closures caused by COVID-19. Retrieved from https://en.unesco.org/covid19/educationresponse

[26] Arnado, J. M., Jabal, R. F., Poa, M. R. J. A., \& Viray, T. C. (2021). Trust in pandemic-induced online learning: Competitive advantage of closure and reputation. International Journal of Sociology of Education, 10(2), 193-217. https://doi.org/10.17583/rise.2021.7088

[27] Asri, D. N. (2021). Early Reading Learning for Special Needs Students: Challenges on Inclusive Primary School during COVID-19 Pandemic. 5(August), 1062-1074.

[28] Ayu, D., Utami, P., \& Setiawan, T. (2021). Reading Non-Literary Text Distance Learning at Junior High School Level. 10(2), 335344. https://doi.org/10.23887/jpi-undiksha.v10i2.31186

[29] B, D. P. V, \& Abhijith, A. N. (2014). Teacher-Student Relationship and Job Attitude : A Comparative Study on Literature Readers and Non Readers among School Teachers. 3(9), 32-40.
[30] Bayod, R., \& June, E. (2021). Bracing for the Ne Normal or Post Normal: Challenges and Aspirations of Indigenous Parents for the Education of their Children Bracing for the new normal or postnormal? Challenges and aspirations of indigenous parents for education of their children. Eubios Journal of Asian and International Bioethics., 31(3), 161-169.

[31] Bertram, C. (2006). Exploring teachers' reading competences: A South African case study. International Journal of Phytoremediation, 21(1), 5-18. https://doi.org/10.1080/02680510500467874

[32] Equipado, E. B., \& Asis-gilbas, S. (2021). Lived Experiences of the Elementary Teachers in a Remote School. 3, 1-10.

[33] Forlin, C. (2010). Teacher education for inclusion: Changing paradigms and innovative approaches. In Teacher Education for Inclusion: Changing Paradigms and Innovative Approaches. https://doi.org/10.4324/9780203850879

[34] Guan, A. G. R., \& Benavides, N. G. (2021). Parent-TeacherLearner Collaboration in Facilitating Modular Instruction. United International Journal for Research \& Technology, 02(07), 80-89.

[35] Halcomb, E. J., \& Davidson, P. M. (2006). Is verbatim transcription of interview data always necessary? Applied Nursing Research, 19(1), 38-42. https://doi.org/10.1016/j.apnr.2005.06.001

[36] Hurry, J., \& Sylva, K. (2007). Long-term outcomes of early reading intervention. Journal of Research in Reading, 30(3), 227248. https://doi.org/10.1111/j.1467-9817.2007.00338.x

[37] Kennedy, E., Dunphy, E., Dwyer, B., Hayes, G., McPhillips, T., Marsh, J., O'Connor, M., \& Shiel, G. (2012). Literacy in early childhood and primary education (3-8 Years). National Council for Curriculum and Assessment (NCCA), 15, 1-412.

[38] Kintanar, F. C., Elladora, S. T., \& Cuizon, F. R. (2021). Plight of the Parents of the Filipino Learners in the Implementation of the Modular Distance Learning. International Journal of Educational Science and Research, 11(2), 35-48. https://doi.org/10.24247/ijesrdec20216

[39] Lituanas, P. M., Jacobs, G. M., \& Renandya, W. A. (2001). (2001). . An investigation of extensive reading with remedial students in a Philippines secondary school. International Journal of Educational Research, 35 , 217-225. International Journal of Educational Research, 217-225.

[40] Mahony, D., Singson, M., \& Mann, V. (2000). Reading ability and sensitivity to morphological relations. Annals of Operations Research, 97(1-4), 131-141. https://doi.org/10.1023/A

[41] Mantilla, R. J. (2020). Demographic location: touched the reading performance of pupils. March. https://scholar.google.com/scholar?hl=en\&as_sdt=0\%2C5\&q=non -readers+academic+achievement+in+the+philippines\&btnG=

[42] Matshe, P. F. A. (2014). Challenges of Parental Involvement in Rural Public Schools in Ngaka Modiri Moleme District of North West Province (South Africa). International Journal of Humanities Social Sciences and Education (IJHSSE), 1(6), 2349. www.arcjournals.org

[43] Mirasol, R. G., \& Topacio, K. N. (2021). Reading Perceptions, Needs, and Practices among Parents of an Urban Poor Community in the Philippines. Reading Psychology, 42(7), 777-787. https://doi.org/10.1080/02702711.2021.1939822

[44] Mohammadzadeh MohammadAbadi, A., Dabaghi, A., \& Tavakoli, M. (2012). The effects of simultaneous use of preplanning along +/-Here-and-Now dimension on fluency, complexity, and accuracy of Iranian EFL learners' written performance. International Journal of Research Studies in Language Learning, 2(3). https://doi.org/10.5861/ijrsll.2012.168

[45] Palma, A. J., \& Madrigal, D. (2021). An Exploratory Inquiry into the Second Language Acquisition of Junior High School NonReaders. Technium Social Sciences Journal, 17, 235-243. https://scholar.google.com/scholar?hl=en\&as_sdt=0\%2C5\&q=non -readers+academic+achievement+in+the+philippines\&btnG=

[46] Perfetti, C. (2007). Reading Ability (SSR) scanned.pdf. In Scientific Studies of Reading (Vol. 11, Issue 4, pp. 375-383).

[47] Poland Blake, D. (1995). Transcription quality as an aspect of rigor in qualitative research. Qualitative Inquiry, 1(3), 290-310. 
[48] Pretorius, E. J. (2000). Reading and the Unisa student: is academic performance related to reading ability? Progressio, 22(2), 35-48.

[49] Salamuddin, A. A. (2021). Comparative Analysis Of Students Perceptions In Modular Distance Learning Approach Versus FaceTo-Face Learning Approach Of Mindanao State University - Sulu. Open Access Indonesia Journal of Social Sciences, 4(1), 132-142. chrome-

extension://efaidnbmnnnibpcajpcglclefindmkaj/viewer.html?pdfur $\mathrm{l}=\mathrm{https} \% 3 \mathrm{~A} \% 2 \mathrm{~F} \% 2 \mathrm{Fwww}$.researchgate.net $\% 2 \mathrm{Fprofile} \% 2 \mathrm{FFitzger}$ ald-

Kintanar\%2Fpublication\%2F354648567_PLIGHT_OF_THE_PA RENTS OF THE FILIPINO_LEARNERS_IN_THE_IMPLEME NTATION_OF_THE_MODULAR_DISTANCE_LEARNING\%2
Flinks\%2F61441fdfa609b152aa157e7e\%2FPLIGHT-OF-THEPARENTS-OF-THE-FILIPINO-LEARNERS-IN-THEIMPLEMENTATION-OF-THE-MODULAR-DISTANCELEARNING.pdf\&clen $=1017606$

[50] Whitten, C., Labby, S., \& Sullivan, S. L. (2016). The impact of Pleasure Reading on Academic Success. The Journal of Multidisciplinary Graduate Research, 2(4), 48-64.

[51] Woodward, M. M., \& Talbert-Johnson, C. (2009). Reading Intervention Models: Challenges of Classroom Support and Separated Instruction. The Reading Teacher, 63(3), 190-200. https://doi.org/10.1598/rt.63.3.2

[52] Zhan, Z., Zhang, L., Mei, H., \& Fong, P. S. W. (2016). Online learners' reading ability detection based on eye-tracking sensors. Sensors (Switzerland), 16(9). https://doi.org/10.3390/s16091457 